\title{
The Roles of Endogenous Opioids in the Inhibitory Action of the Hippocampus on Preovulatory of Luteinizing Hormone in Rats
}

\author{
Yutaka ENDO*, Kayoko JINNAI and Fukuko KIMURA \\ Department of Physiology, and Oral and Maxillofacial Surgery*, \\ Yokohama City University School of Medicine, \\ Yokohama 236, Japan
}

\begin{abstract}
Whether endogenous opioid peptides were involved in the inhibitory action of the hippocampus (HPC) on luteinizing hormone (LH) release was studied examining the effect of naloxone, an opioid antagonist, on the inhibitory action of electrical stimulation of the HPC and also by examining the effect of metenkephalin administration in the HPC, on preovulatory release of $\mathrm{LH}$ in proestrous rats. In rats treated with saline at $13: 00 \mathrm{~h}$, either sham stimulation or electrical stimulation of the dorsal HPC, which was performed acutely under ether anesthesia, significantly inhibited the afternoon rise in serum LH. In animals treated with naloxone at a dose of $2.0 \mathrm{mg} / \mathrm{kg}$ body weight, the afternoon rise in $\mathrm{LH}$ appeared smaller than that in the control group. However, statistical analysis showed no significant difference in LH values compared to the control group. Direct administration of met-enkephalin at a dose of $10 \mu \mathrm{g}$ at $13: 00 \mathrm{~h}$ through a chronically implanted cannula in the HPC did not induce any significant change in the afternoon rise in LH, regardless of whether it induced behavioral seizures or not. The results suggest that opioid peptides in the HPC do not play a significant role in the inhibitory action of HPC on LH release. Opioids existing in areas other than the HPC may play a certain, but small role.
\end{abstract}

Electrical stimulation of the hippocampus (HPC) has been shown to reduce the preovulatory release of luteinizing hormone $(\mathrm{LH})$ and the incidence of spontaneous ovulation in proestrous rats (Velasco \& Taleisnik, 1969, Gallo et al., 1971,

Received March 16, 1990.

All correspondence should be addressed to: FUKUKO KIMURA, Second Department of Physiology, Yokohama City University School of Medicine, 3-9 Fukuura, Kanazawa-ku, Yokohama 236 Japan.
Kawakami et al., 1972). Similar stimulation of the HPC also prevented ovulation normally observed after stimulation of the medial preoptic area in persistent estrous rats in continuous illumination and in ovulation-blocked proestrous rats with pentobarbital sodium (Velasco \& Taleisnik, 1969, Kawakami et al., 1973).

There is an indication that the inhibitory action of the HPC stimulation is related to the HPC seizure discharges. The mere insertion of an electrode in the HPC 
produced an EEG seizure pattern in this area, spreading to the neocortex and the amygdala (Kawakami et al., 1972), suggesting that the inhibitory action of the HPC stimulation which was reported from the acute experiments was correlated with HPC seizures. Further, stimulation of the HPC with chronically implanted electrodes did not inhibit ovulation when a subthreshold current to induce HPC seizure discharges was used as the stimulation intensity (Kawakami et al., 1972), but inhibited it when a threshold current was used to induce seizure discharge (Kawakami \& Terasawa, 1974).

On the other hand, opioids have been suggested as playing an important role in the regulation of the activity of the HPC. Electrophysiological studies have demonstrated excitatory effects of opioids on the HPC neurons (Nicoll et al., 1977, Zieglgänsberger et al., 1979, Haas \& Ryall, 1980, Dunwiddie et al., 1980, Gahwiler, 1980, Henriksen et al., 1982). Intracerebroventricular administration of opioids has been shown to induce EEG seizure discharges of the HPC (Henriksen et al., 1978, Snead \& Bearden, 1982), and direct administration of opioid or opioid agonist into the HPC caused convulsions (Cain \& Corcoran, 1984, 1985, Lee et al., 1988). Further, these opioid effects were antagonized by opioid antagonists as naloxone (Henriksen et al., 1978, Cain \& Corcoran 1984, Snead \& Bearden, 1982, Lee et al., 1988).

The purpose of this study was to determine whether endogenous opioid peptides are involved in the inhibitory action of the HPC on LH release. This issue was approached by examining whether naloxone will interfere with the inhibitory effect of the HPC stimulation on the preovulatory surge of LH secretion and whether direct injection of opioid will affect the LH surge.

\section{Materials and Methods}

\section{Animals}

Female Wistar-Imamichi rats obtained from Animal Reproduction Research Co., Urawa, at 7-8 weeks of age were housed four to five per cage under controlled lighting (lights on from $5: 00$ to $19: 00 \mathrm{~h})$ and temperature $\left(24^{\circ} \mathrm{C}\right)$ and allowed free access to food and water. Vaginal smears from each rat were obtained daily in the morning.

\section{Electrical Stimulation Experiment}

Animals in proestrus after having exhibited 2 or more consecutive 4-day estrous cycles were implanted with an intraatrial catheter of silicone tubing (Dow Corning) through the jugular vein, and then were fixed to the stereotaxic apparatus, received an incision of the head skin and had a hole drilled in the skull. These procedures were performed under ether anesthesia between $12: 00$ and $13: 00 \mathrm{~h}$. The first blood sample $(300 \mu 1)$ was collected and replaced with an equal volume of heparinized saline (saline-treated) or of heparinized saline containing naloxone (Sigma Chemical Co.) (naloxone-treated) at a dose of $2.0 \mathrm{mg} / \mathrm{kg}$ body weight. Immediately after the first blood sampling, a stimulating electrode was inserted into the dorsal HPC, according to the atlas of Albe-Fessard et al. (1966), followed by electrical stimulation in a group of animals (stimulation group), but not in another group (sham stimulation group). A third group of animals did not receive even the insertion of an electrode (control group). All three groups of animals remained in the stereotaxic apparatus under ether anesthesia for another $30 \mathrm{~min}$ which was the period for electrical stimulation. The second blood sampling was performed at the end of this 30-min period and the electrode withdrawn. Blood sampling at l-hour intervals was started at $14: 00 \mathrm{~h}$ and continued until $20: 00 \mathrm{~h}$.

The stimulating electrode used in this series of experiments was a concentric bipolar electrode consisting of a wire insulated except for the $0.1 \mathrm{~mm}$ tip $(0.13 \mathrm{~mm}$ in diameter $)$ which served as the cathode and an outer barrel $(0.15 \mathrm{~mm}$ exposed surface) which served as the anode. Electrical stimulation consisting of a monophasic square wave at a pulse duration of $0.1 \mathrm{~ms}$ and a frequency of $100 \mathrm{~Hz}$ was applied for $30 \mathrm{~min}$ 
in $30 \mathrm{sec}$ periods alternating with $30 \mathrm{sec}$ rest periods. A $100 \mu \mathrm{A}$ current was employed.

\section{Met-Enkephalin Administration Experiment}

The guide cannula was made of stainless steel tube with a $0.65 \mathrm{~mm}$ outer diameter and was stereotaxically implanted unilaterally into the dorsal HPC under sodium pentobarbital anesthesia. The cannula was fixed to the skull with dental cement and stainless steel screws. The inner cannula with a $0.30 \mathrm{~mm}$ outer diameter was arranged so as to protrude approximately $0.5-\mathrm{mm}$ beyond the tip of the guide cannula. The guide cannula was plugged with a dummy inner cannula until the day of the experiment.

The animals in proestrus, after having exhibited 2 or more consecutive estrous cycles following implantation of the guide cannula, were implanted with an intraatrial cannula under ether anesthesia in the morning. The first blood sample $(300 \mu \mathrm{l})$ was collected at $12: 00 \mathrm{~h}$ and met-enkephalin (Peptide Institute, Minoo) at a dose of $10 \mu \mathrm{g}$ dissolved in a volume of $1 \mu \mathrm{l}$ sterile $0.9 \%$ saline was injected at $13: 00 \mathrm{~h}$ immediately after the second sampling. The blood sampling was performed at $1-\mathrm{h}$ intervals afterwards until $20: 00 \mathrm{~h}$

\section{Hormone Assay}

Serum concentrations of $\mathrm{LH}$ were measured by the double-antibody radioimmunoassay using materials supplied by the NIDDK. The refer- ence standard was NIDDK rat LH-RP-1, but the amounts of LH were expressed in terms of NIH-LH-S1. The within- and between-assay variances for $\mathrm{LH}$ assays, which were calculated from 5 replicate samples of a standard pooled serum with a mean $\mathrm{LH}$ concentration of 5.81 $\mathrm{ng} / \mathrm{ml}$ in each assay, were $5.1 \%$ (mean for 6 assays) and $13.8 \%$, respectively.

\section{Histology}

After the final bleeding at $20: 00 \mathrm{~h}$, the rats were anesthetized with ether and perfused with $10 \%$ buffered formalin. The site of the electrode was microscopically identified in frozen sections of the brain.

\section{Statistical Analysis}

Two-way analysis of variance and Duncan's multiple range test were used to test the statistical significance of fluctuations over time in the mean hormone values for each sampling time. Student's $t$-test was used to test the significance of difference between the treatment groups.

\section{Results}

\section{Electrical Stimulation Experiment} This sites of electrical stimulation in the HPC are shown schematically in
1) Saline

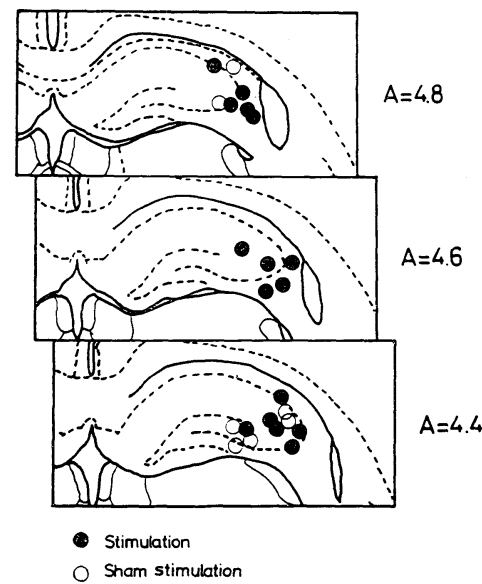

2) Naloxone

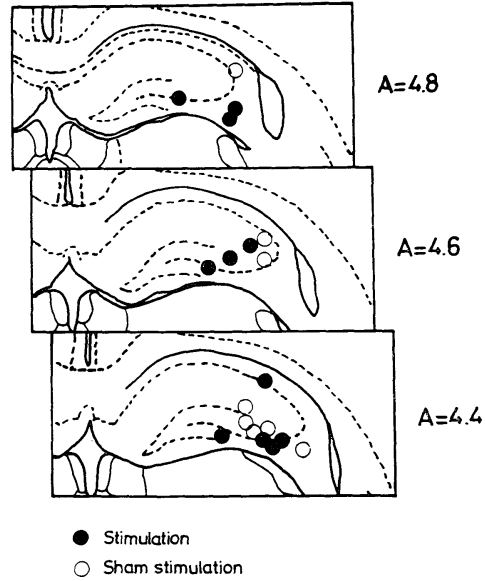

Fig. 1. Schematic illustrations showing the sites of electrical stimuration, as indicated by the tip of the electrode in the hippocampus. The left panel shows the sites for salinetreated rats and the right shows those for naloxone-treated rats. 
Figure 1, and the mean $( \pm S E)$ of serum concentrations of $\mathrm{LH}$ for each sampling time is shown diagramatically in Figure 2 for saline-treated and in Figure 3 for naloxone-treated rats.

Control group: In animals in the control group, treated with either saline or naloxone, there was a significant increase in $\mathrm{LH}$ in the afternoon. Mean $\mathrm{LH}$ peaked at $18: 00$ or $17: 00 \mathrm{~h}$ in saline $(\mathrm{p}<0.001)$ and naloxone $(\mathrm{p}<0.05)$ - treated animals, respectively, with significant increase compared to the values at $13: 00-16: 00 \mathrm{~h}$. The peak LH time was apparently delayed by 1 or 2 hours compared to that in the met-enkephalin administration experiment described later. The major factor responsible for this delay was probably anesthesia with ether (Blake, 1974). There was no significant differences in the mean LH in naloxone-treated animals compared to the value in saline-treated control animals at corresponding times.
Sham stimulation group: Saline-treated animals in the sham stimulation group showed a significant afternoon rise in $\mathrm{LH}$, peaking at 18:00 and $19: 00 \mathrm{~h}$ with significantly greater values than those at $13: 00-17: 00 \mathrm{~h} \quad(\mathrm{p}<0.01$ or 0.05 for the value at $18: 00 \mathrm{~h}$ ) and at $13: 00-16: 00 \mathrm{~h}$ $(\mathrm{p}<0.01$ for the value $19: 00 \mathrm{~h})$. The mean $\mathrm{LH}$ values at $18: 00$ and $19: 00 \mathrm{~h}$ were significantly smaller than those in the control group $(\mathrm{p}<0.05)$. In naloxonetreated animals, the sham stimulation group showed a significant afternoon increase, peaking at $17: 00$ and $18: 00 \mathrm{~h}$ with significantly greater values than those at $13: 00-15: 00 \mathrm{~h}(\mathrm{p}<0.05$ for the value at $17: 00 \mathrm{~h})$ and at $13: 00-16: 00 \mathrm{~h}(\mathrm{p}<$ 0.01 or 0.05 for the value at $18: 00 \mathrm{~h})$. The values in the sham stimulation group were apparently smaller than those in the control group treated with naloxone, but no values were signicantly different from those in the control group.

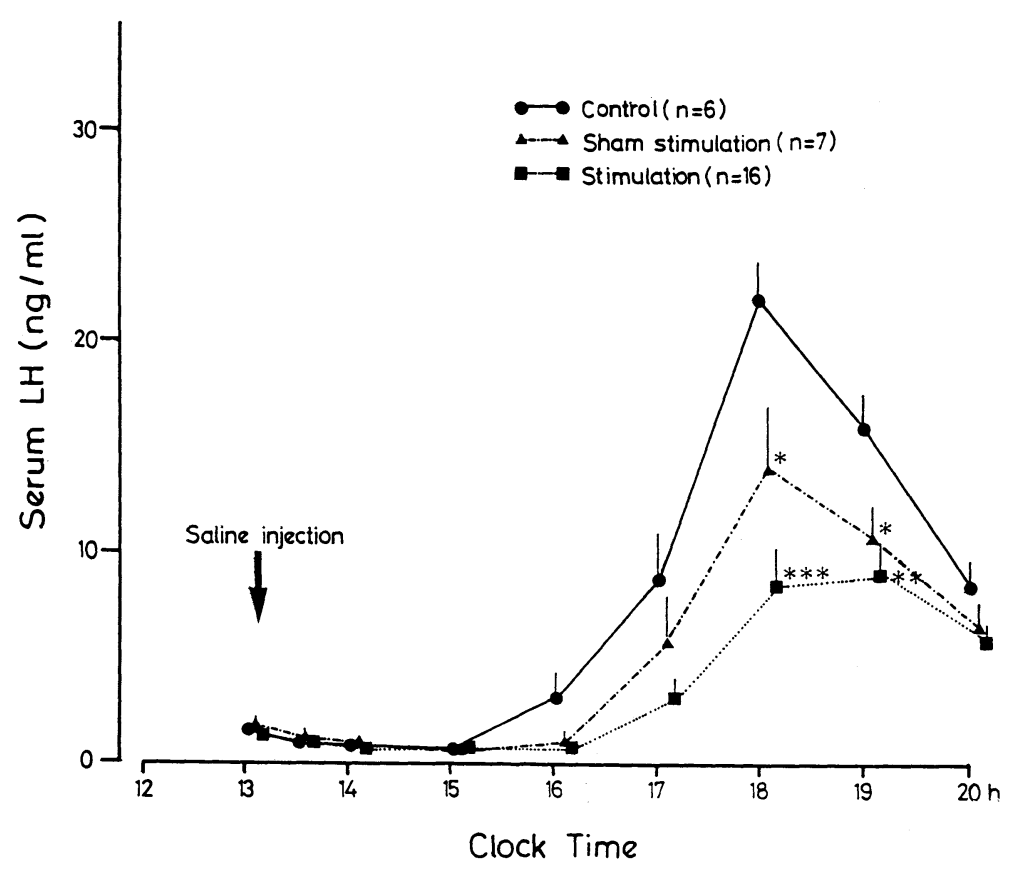

Fig. 2. Time course of serum concentrations of $\mathrm{LH}$ in saline-treated rats. The points and the vertical lines represent the mean and SE. Asterisks indicate significant difference from rats in the control group at corresponding times; $* \mathrm{p}<0.05, * * \mathrm{p}<$ 0.01 and $* * * \mathrm{p}<0.001$. 
Stimulation group: The stimulation group, either saline- or naloxone-treated animals, showed a small but significant afternoon rise. In saline-treated animals, the mean $\mathrm{LH}$ value peaked at 18:00 and $19: 00 \mathrm{~h}$ with a significant difference compared to values at $13: 00-17: 00 \mathrm{~h}(\mathrm{p}$ $<0.01$ or 0.05 for the value at $18: 00 \mathrm{~h}$ and $\mathrm{p}<0.001$ or 0.01 for the value at $19: 00 \mathrm{~h})$. The values at $18: 00$ and $19: 00 \mathrm{~h}$ were significantly $(\mathrm{p}<0.001$ and 0.01 , respectively) smaller than those in the control group at corresponding times, but did not differ from those in the sham group. Naloxone-treated animals showed peak values at $18: 00$ and $19: 00 \mathrm{~h}$ with significant differences compared to values at $13: 00-16: 00 \mathrm{~h} \quad(\mathrm{p}<0.05)$. The values in the stimulation group appeared markedly smaller than the values in either the control or sham stimulation group, as in the saline-treated animals. However, no values were significantly smaller than those in the control or the sham group, except the value at $19: 00 \mathrm{~h}$ that was significantly smaller than the value in the control group $(\mathrm{p}<0.05)$.

\section{Met-Enkephalin Administration Experiment}

Injection of met-enkephalin into the dorsal HPC evoked wet-dog shakes in 7 out of 20 rats, and in one rat out of 7 , resulted in bilaterally generalized convulsions. The sites of met-enkephalin injection the HPC are shown schematically in Figure 4 with respect to the behavioral effect. The mean $( \pm S E)$ of serum concentrations of $\mathrm{LH}$ for each sampling time is shown diagramatically in Figure 5 with respect to the behavioral effect, too.

There was a significant afternoon increase in $\mathrm{LH}$ in the saline-injected animals. LH peaked at $16: 00$ or $17: 00 \mathrm{~h}$, with significant differences from values at 12:00$15: 00 \mathrm{~h}$. Met-enkephalin-injected animal behavioral seizures showed a significant afternoon increase in $\mathrm{LH}$, peaking at 16:00

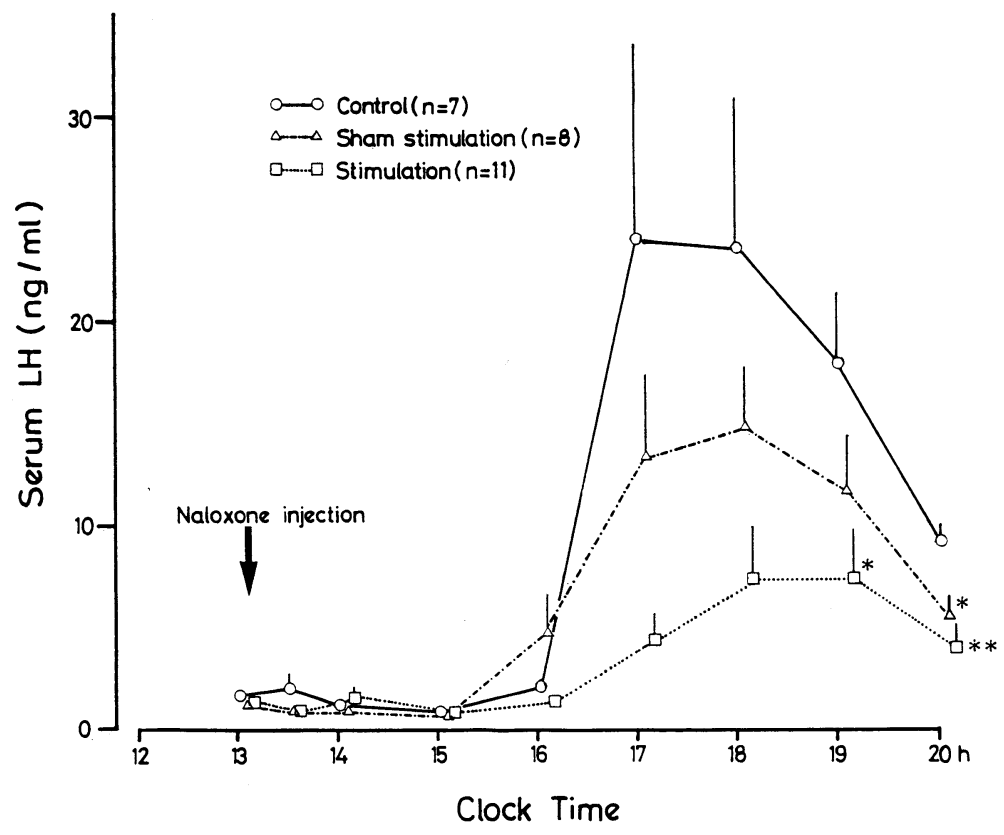

Fig. 3. Time course of serum concentrations of $\mathrm{LH}$ in naloxone-treated rats. For further details, see Fig. 2. 
and $17: 00 \mathrm{~h}$ with significant differences from values at $12: 00-15: 00 \mathrm{~h}$. There were no significant differences in the values in the met-enkephalin treated animals, either with or without behavioral seizures compared to values at corresponding times in salinetreated animals.

\section{Discussion}

The present study supports the earlier finding that electrical stimulation of the HPC reduces the preovulatory release of $\mathrm{LH}$ in rats. $\mathrm{LH}$ release in saline-treated animals was significantly reduced either by sham stimulation or electrical stimulation of the dorsal HPC.

In naloxone-treated animals, neither sham stimulation nor electrical stimulation was effective in reducing $\mathrm{LH}$ release, although there was an apparent tendency

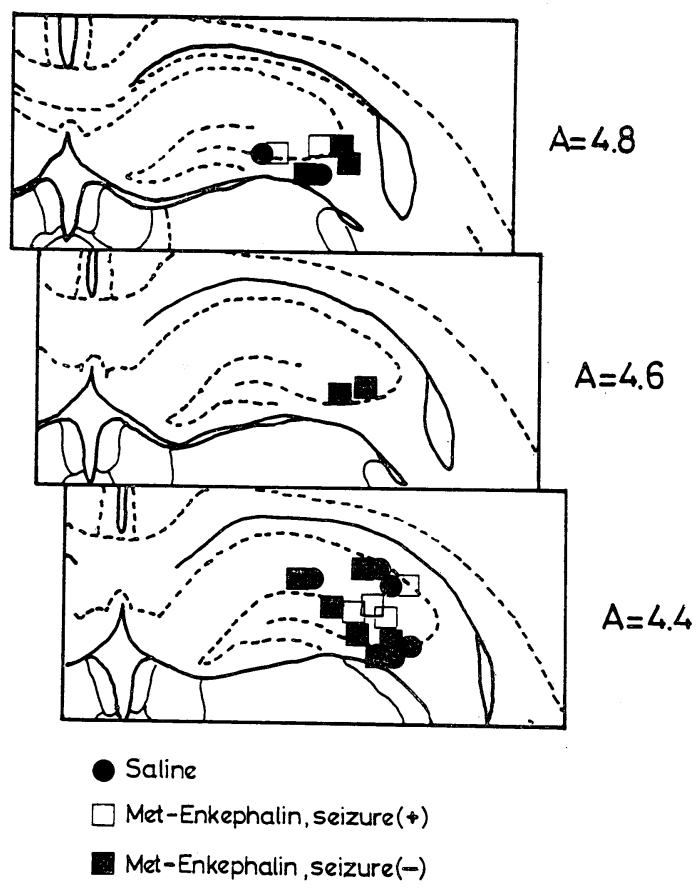

Fig. 4. Schematic illustrations showing the sites of met-enkephalin injection, as indicated by the tip of the cannula in the hippocampus. toward reduction. This decrease in the effect of both sham and electrical stimulation of the HPC could have been interpreted in two ways. First, it was possible that naloxone reduced the opioid activity in the HPC and thus the excitability of the HPC was decreased. The second possibility was that naloxone reduced the opioid activity in the preoptic-hypothalamic area and thus the inhibitory action of the HPC on LH release was not able to occur.

The first possibility was likely in the light of the distribution of opioid immunoreactivity and opioid receptor subtypes in the HPC (Meibach \& Haayani, 1980, Crain et al., 1986, McLean et al., 1987). Further, electrophysiological studies have demonstrated a role of $\mu$-receptor in evoking seizure activities (Henriksen et al., 1978, Snead \& Bearden 1982, Cain \& Corcoran, 1984, Lee et al., 1988) and in increasing excitability of the HPC (Nicoll et al., 1977, Zieglgänsberger et al., 1979, Gahwiler, 1980, Haas \& Ryall, 1980, Dunwiddie et al., 1980, Henriksen et al., 1982). Opioid was then injected into the HPC to determine whether the opioid activity in the HPC was related to the HPC action in inhibiting $\mathrm{LH}$ release. If the inhibition of $\mathrm{LH}$ release occurred in response to the injection of met-enkephalin into the HPC, the first possibility concerning the stimulation experiment is more likely. Met-enkephalin injection at a dose of $10 \mu \mathrm{g}$ evoked behavioral seizures in about $30 \%$ of the animals as described previously for metenkephalin (Cain and Corcoran, 1984) and $\mu$-receptor agonist (Lee et al., 1988). However, no change was seen in the preovulatory secretion of $\mathrm{LH}$ in these animals. Since these behavioral seizures have been closely correlated with EEG seizure discharges in the HPC (Henriksen et al., 1978, Snead \& Bearden, 1982, Cain \& Corcoran, 1984, Lee et al., 1988), the results imply that the HPC seizure discharges are not profoundly involved in the mechanism of the inhibitory 
effect of HPC stimulation. Further, the present finding that the $\mathrm{LH}$ secretion in animals that did not show signs of behavioral seizures after met-enkephalin injection was not changed significantly suggests a negligible role of opioids existing in the HPC in the inhibitory action of HPC. Therefore, the first possibility we suggested can be reasonably denied.

On the other hand, considerable concentrations of beta-endorphin and enkephalin, and their receptors exist in the septalpreoptic-hypothalamic region (Uh1 et al., 1978, Woodhams et al., 1983, Cuello, 1983) and have been believed to mediate various kinds of inhibition of $\mathrm{LH}$ release, such as gonadal steroid hormones (see review by Kalra, 1986) and stress (Nikolarakis et al., 1988). This region receives projections from the HPC through two distinct pathways: the descending column of the fornix and the medial corticohypothalamic tract (Meibach $\&$ Siegel, 1977). Both of these pathways have been shown to be involved in transmitting the inhibitory influence of the HPC on LH release (Velasco \& Taleisnik, 1969, Kawakami \& Kimura, 1975). It is therefore possible that endogenous opioids distributed in the septal-preoptic-hypothalamic region somehow mediate this HPC influence on LH release. Decreases in the opioid activity in these areas due to naloxone would have been related with the reduction of the inhibition.

However, the apparent tendency toward inhibition which was seen in both the sham and electrical stimulation groups of naloxone-treated animals suggests the possibility that naloxone actually does not affect the inhibitory action of the HPC. It is probable that large variations in the $\mathrm{LH}$ value observed in naloxone-treated animals account for the statistical insignificance of differences between control and stimulation groups. In addition, it was noticeable that electrical stimulation of the HPC produced

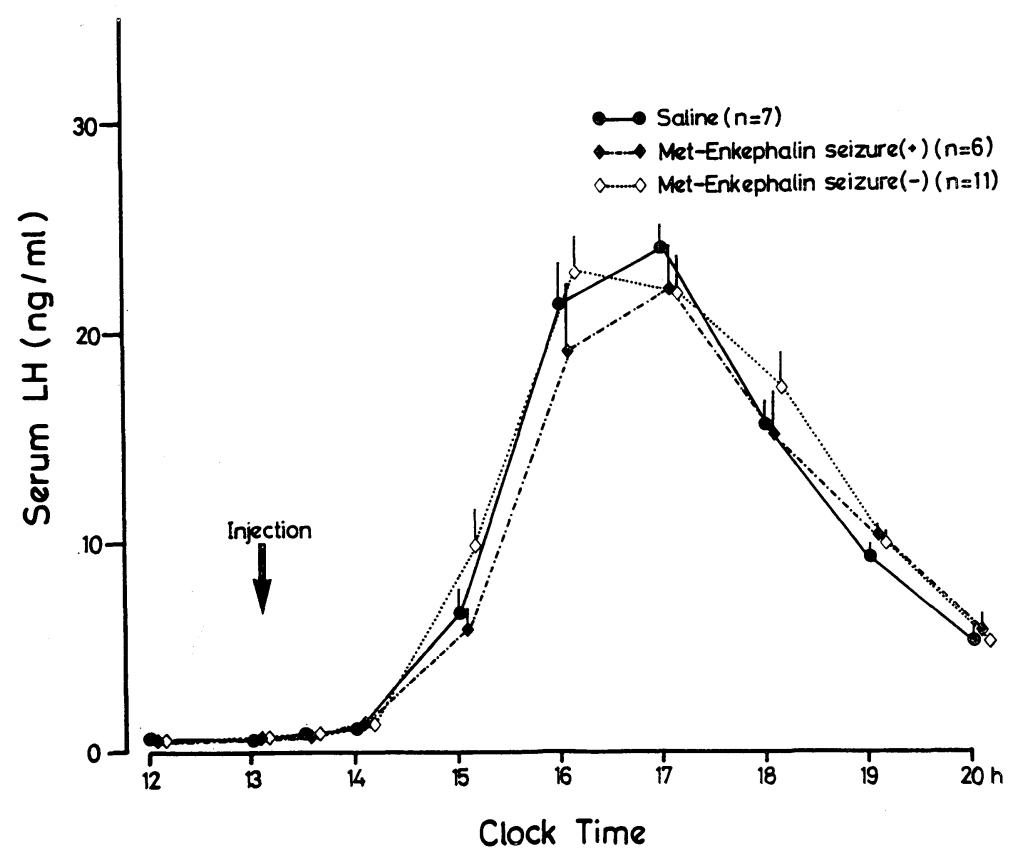

Fig. 5. Time course of serum concentrations of $\mathrm{LH}$ in rats injected with met-enkephalin. For further details, see Fig. 2. 
almost the same $\mathrm{LH}$ values in both the salineand naloxone-treated animals: i. e., no $\mathrm{LH}$ values in animals in the stimulation group were significantly different in the two groups, although not described in Results.

In view of the results of one of our earlier studies, we suggested a significant role of cholinergic transmission in the expression of the HPC inhibition of preovulatory LH release (Kawakami et al., 1976). Atropine treatment at a dose of $200 \mathrm{mg} / \mathrm{kg}$ body weight, which was subthreshold to block ovulation, abolished the inhibitory effect of electrical stimulation of the HPC on preovulatory $\mathrm{LH}$ release. On the basis of rather classical studies attempting to map the cholinergic neurons in the rat brain (Lewis \& Shute, 1967), recent studies have disclosed a septo-hippocampal and a diagonal band-HPC projection (see review by Bjorklund et al., 1984). In addition, the HPC is characterized by a high concentration of putative muscarinic receptors. Therefore, it is very likely that the most important neural transmission in maintaining the HPC activity related to the inhibition of LH is cholinergic afferents, but not intrinsic opioidergic neurons.

\section{References}

Albe-Fessard, D., F. Stutinsky and S. Libouban (1966). Atlas Stereotaxique du Diencephale du Rat Blanc. Editions de Centre National de la Recherche Scientifique, Paris.

Björklund A., T. Hörkfelt and M. J. Kuhar (1984). Classical transmitters and transmitter receptors in the CNS, Part II. In: Handbook of Chemical Neuroanatomy (A. Björklund and T. Hökfelt, eds.), Elsevier, Amsterdam-New York-Oxford, pp. 1-50.

Blake C. A. (1974). Differentiation between the "critical period", the "activation period" and the "potential activation period" for neurohumoral stimulation of $\mathrm{LH}$ release in proestrous rats. Endocrinology 95, 572-578.

Cain, D. P. and M. E. Corcoran (1984). Intracerebral $\beta$-endorphin, met-enkephalin and morphin : Kindling of seizures aud handlinginduced potentiation of epileptiform effects. Life Sci. 34, 2535-2542.

Cain, D. P. and M. E. Corcoran (1985). Epileptiform effects of met-enkephalin, $\beta$ endorphin and morphine: Kindling of generalized seizures and potentiation of epileptiform effects by handling. Brain Res. 338, 327336.

Crain, B. J., K.-J. Chang and J. O. McNamara (1986). Quantitative autoradiographic analysis of mu and delta opioid binding sites in the rat hippocampal formation. J. Comp. Neurol. 246, $170-180$

Cuello, A. C. (1983). Central distribution of opioid peptides. British Med. Bull. 39, 1116.

Dunwiddie, T., A. Mueller, M. Palmer, J. Stewart and B. Hoffer (1980). Electrophysiological interactions of enkephalins with neuronal circuitry in the rat hippocampus. I. Effects on pyramidal cell activity.

Gahwiler, B. H. (1980). Excitatory action of opioid peptides and opiates on cultured hippocampal pyramidal cells. Brain Res. 194, 193203.

Gallo, R. V., J. H. Johnson, B. D. Goldman, D. I. Whitmoyer and C. H. Sawyer (1971). Effects of electrochemical stimulation of the ventral hippocampus on hypothalamic electrical activity and pituitary gonadotropin secretion in female rats. Endocrinology 89, 704-713.

Haas, H. L. and R. W. Ryall (1980). Is excitation by enkephalins of hippocampal neurones in the rat due to presynaptic facilitation or to disinhibition? J. Physiol. (Lond.) 308, 315-330.

Henriksen, S. J., F. E. Bloom, F. McCoy, N. Ling and R. Guillemin (1978). $\beta$-Endorphin induces nonconvulsive seizures. Proc. Natl. Acad. Sci. USA. 75, 5221-5225.

Henriksen, S. J., G. Chouvet, J. McGinty and F. E. Bloom (1982). Opioid peptides in the hippocampus: Anatomical and psychological considerations. Ann. New York Acad. Sci. 398, 207-220.

Kalra, S. P. (1986). Neural circuitry involved in the control of LHRH secretion: A model for preovulatory LH release. In: Frontiers in Neuroendocrinology, vol. 9 (W. F. Ganong and L. Martini, eds.), Raven Press, Now York. pp. 31-75. 
Kawakami, M. and F. Kimura (1975). Acute and chronic effects of the fornix section on cyclic gonadotropin secretion and ovulation in the rat. Endocrinol. Japon. 22, 43-48.

Kawakami, M., F. Kimura and S. Kawagoe (1976). Cholinergic and serotonergic neural links and the inhibitory effects of hippocampus, lateral amygdala and central gray matter on gonadotropin release. Endocrinol. Japon. 23, 11-21.

Kawakami, M., F. Kimura and K. Wakabayashi (1972). Electrical stimulation of the hippocampus under the chronic preparation and changes of LH, FSH and prolactin levels in serum and pituitary. Endocrinol. Japon. 19, 85-96.

Kawakami, M. and E. Terasawa (1974). Role of limbic forebrain structures on reproductive cycles. In: Biological Rhythms in Neuroendocrine Activity (M. Kawakami, ed.), Igaku Shoin, Tokyo. pp. 197-219.

Kawakami M., E. Terasawa, F. Kimura and K. Wakabayashi (1973). Modulating effect of limbic structures on gonadotropin release. Neuroendocrinology 12, 1-16.

Lee, P. H. K., J. Obie and J. -S. Hong (1988). Intrahippocampal injections of a specific $\mu$-receptor ligand PL017 produce generalized convulsions in rats. Brain Res. 441, 381-385.

Lewis, P. R. and C. C. D. Shute (1967). The cholinergic limbic system: Projections to hippocampal formation, medial cortex, nuclei of the ascending cholinergic reticular system, and the subfornical organ and supra-optic crest. Brain, 90, 521-540.

McLean, S., R. B. Rothman, A. E. Jacobson, K. C. Rice and M. Herkenham (1987). Distribution of opiate receptor subtypes and enkephaline and dynorphin immunoreactivity in the hippocampus of squirrel, guinea pig, rat, and hamster. J. Comp. Neurol. 255, 497510 .
Meibach, R. C. and S. Haayani (1980). Localization of naloxone-sensitive $[3 \mathrm{H}]$ dihydromorphin binding sites within the hippocampus of the rat. Eur. J. Pharm. 68, 175-179.

Meibach, R. C. and A. Siegel (1977). Efferent connections of the hippocampal formation in the rat. Brain Res. 124, 197-224.

Nicoll, R. A., G. R. Siggins, N. Ling, F. E. Bloom and R. Guillemin (1977). Neuronal actions of endorphins and enkephalins among brain regions: A comparative microiontophoretic study. Proc. Natl. Acad. Sci. USA 74, 2584-2588.

Nikolarakis, K. E., O. F. X. Almeida, D. J. S. Sirinathsinghji and A. Herz (1988). Concomitant changes in the in vitro and in vivo release of opioid peptides and luteinizing hormone-releasing hormone from the hypothalamus following blockade of receptors for corticotropin-releasing factor. Neuroendocrinology 47, 545-550.

Snead, O. C. III and L. J. Bearden (1982). The epileptogenic spectrum of opiate agonists. Neuropharmacol. 21, 1137-1144.

Uh1, G. R., S. R. Childers and S. H. Snyder (1978). Opioid peptides and the opiate receptor. In : Frontiers in Neuroendocrinology, Vol. 5 (W. F. Ganong and L. Martini, eds.), Raven, Press, New York. pp. 289-328.

Velasco, M. E. and S. Taleisnik (1969). Effect of hippocampal stimulation on the release of gonadotropin. Endocrinology 85, 1154-1159.

Woodhams, P. L., G. W. Roberts, J. M. Polak and T. J. Crow (1983). Distribution of neuropeptides in the limbic system of the rat: The bed nucleus of the stria terminalis, septum and preoptic area. Neuroscience 8, 677-703. Zieglgänsberger, W., E. D. French, G. R. Siggins and F. E. Bloom (1979). Opioid peptides may excite hippocampal pyramidal neurons inhibiting adjacent inhibitory interneurons. Science 205, 415-417. 